\title{
Five Years Study of Recurrent Febrile Seizure Risk Factors
}

\author{
Ausi Indriani, ${ }^{1}$ Nelly Amalia Risan, ${ }^{2}$ Titing Nurhayati ${ }^{3}$ \\ ${ }^{1}$ Faculty of Medicine Universitas Padjadjaran, ${ }^{2}$ Department of Child Health Faculty of Medicine \\ Universitas Padjadjaran/Dr. Hasan Sadikin General Hospital Bandung, ${ }^{3}$ Department of Anatomy, \\ Biology Cell and Physiology Faculty of Medicine Universitas Padjadjaran
}

\begin{abstract}
Background: Nearly one-third of febrile seizure patients suffered recurrent febrile seizures. Several risk factors contribute to this recurrence, namely young age, family history of febrile seizures, low body temperature and rapid duration of fever before onset of seizures. Recently, the types of seizure and gender have been stated increasing risk of this recurrence. The objectives of this study was to identify the risk factors of recurrent febrile seizures.

Methods: A descriptive study was carried out by retrieving data from inpatient medical records during the period of January 1st, 2009 to December 31st, 2013 at one of the top referral hospitals in West Java, Indonesia. Variables of this study were the first febrile seizure age, gender, type of febrile seizure, a family history of febrile seizure, a family history of epilepsy, body temperature when febrile seizure occurred and duration of fever before onset of seizure. The collected data were tabulated by frequency and percentage and displayed in tables.

Results: Out of 154 patients with febrile seizures 58 suffered recurrent febrile seizures. Forty three percent had a first febrile seizure at the age of under 12 months, $72 \%$ were male, $46 \%$ had fever less than 24 hours before the onset of seizure, $65 \%$ had complex febrile seizures, $28 \%$ had positive family history of febrile seizures, and $5 \%$ had positive family history of epilepsy.

Conclusions: The risk factors for recurrent febrile seizures are young age, male, rapid duration of fever before onset of seizure and complex febrile seizure.

Keywords: Febrile seizure, recurrent febrile seizure, risk factors
\end{abstract}

\section{Introduction}

Febrile seizure is one of the most common seizures suffered by children with a total prevalence of $2-5 \%{ }^{1}$ According to the International League against Epilepsy (ILAE), febrile seizure is a seizure occurring in association with a febrile illness in the absence of a central nervous system infection or acute electrolyte imbalance in children older than 1 month of age without prior afebrile seizures. ${ }^{2}$ Patients with febrile seizures usually have a good prognosis although this condition makes parents worried.,4 Morbidity and mortality rate of febrile seizures are relatively low; nevertheless febrile seizures also have the risk for death., ${ }^{5,6}$ Patients with febrile seizures also have a high risk for recurrent febrile seizures and epilepsy. ${ }^{1,4,7}$

Nearly one-third of febrile seizure patients suffered recurrentfebrile seizures. ${ }^{1,8}$ Theoretically, there are several risk factors for recurrence of febrile seizures; young age, family history of febrile seizure, low body temperature and rapid duration of fever before onset of seizures. ${ }^{8-10}$ Recently, the type of seizure and gender have been stated increasing risk of recurrent febrile seizure.4 The objectives of this study was to identify the risk factors of recurrent febrile seizures.

\section{Methods}

Data of this descriptive study was retrieved from medical records of recurrent febrile seizure patients who were hospitalized during the period of January 1st, 2009 to December 31st, 2013 at Dr. Hasan Sadikin General Hospital (RSHS) Bandung. The process of collecting medical record data was approved

Correspondence: Ausi Indriani, Faculty of Medicine, Universitas Padjadjaran, Jalan Raya Bandung-Sumedang Km.21, Jatinangor, Sumedang, Indonesia, Phone: +6281266070152 Email: ausi.indriani@gmail.com 
by the Ethics committee of RSHS. The subjects in this study were all the patients with clinical diagnose of recurrent febrile seizures that met the inclusion criteria, i.e. patients who had seizures accompanied by a rise in body temperature above $38^{\circ} \mathrm{C}$ caused by an extra cranium process, children with an age range 1 month to 7 years and did not have a history of afebrile seizures.

The variables of this study were the risk factors for recurrent febrile seizures that consisted of first febrile seizure age, gender, type of febrile seizure, family history of febrile seizure, family history of epilepsy, body temperature when febrile seizures occurred and the duration of fever before onset of seizure. Then, data were processed by using statistical software. The data were calculated in the form of frequency and percentage and arranged in tabular form.

\section{Results}

From the medical record data of febrile seizure patients at RSHS in the period January 1st, 2009 to December 31st, 2013 there were 154 patients with febrile seizures of which $37,6 \%$ were with recurrent febrile seizures (58 patients).

In this study, patients with first febrile

Table 1 Distribution of Risk Factors of Recurrent Febrile Seizure

\begin{tabular}{|c|c|c|}
\hline Variable & $n=58$ & (\%) \\
\hline \multicolumn{3}{|l|}{ Age of first febrile seizure } \\
\hline < 12 months, $\mathrm{n}(\%)$ & 25 & $(43)$ \\
\hline 12-24 months, n (\%) & 22 & (38) \\
\hline$\geq 24$ months, $\mathrm{n}(\%)$ & 5 & (9) \\
\hline Not identified, n (\%) & 6 & $(10)$ \\
\hline \multicolumn{3}{|l|}{ Gender } \\
\hline Male, n (\%) & 42 & $(72)$ \\
\hline Female, n (\%) & 16 & (28) \\
\hline \multicolumn{3}{|c|}{ Duration of fever before onset of seizure } \\
\hline$<24$ hours, $\mathrm{n}(\%)$ & 27 & $(46)$ \\
\hline 24-48 hours, n (\%) & 18 & $(31)$ \\
\hline 49-72 hours, n (\%) & 5 & (9) \\
\hline 73-96 hours, n (\%) & 1 & (2) \\
\hline$\geq 96$ hours, $\mathrm{n}(\%)$ & 4 & (7) \\
\hline Not identified, n (\%) & 3 & (5) \\
\hline \multicolumn{3}{|l|}{ Type of febrile seizure } \\
\hline Simple febrile seizure, $\mathrm{n}(\%)$ & 16 & $(28)$ \\
\hline Complex febrile seizure, n (\%) & 38 & $(65)$ \\
\hline Not identified, n (\%) & 4 & (7) \\
\hline \multicolumn{3}{|l|}{ Family history of febrile seizure } \\
\hline Positive, n (\%) & 16 & $(28)$ \\
\hline Negative, n (\%) & 33 & (57) \\
\hline Not identified, n (\%) & 9 & (15) \\
\hline \multicolumn{3}{|l|}{ Family history of epilepsy } \\
\hline Positive, n (\%) & 3 & (5) \\
\hline Negative, n (\%) & 55 & (95) \\
\hline
\end{tabular}


seizure under the age of 12 months had the highest percentage. The number of male patients had almost doubled compared with female patients. Patients with the duration of febrile seizures less than 24 hours had the highest percentage. The percentage of patients with positive family history of febrile seizures was less than patients with negative family history of febrile seizures. Most of the patients had negative family history of epilepsy.

\section{Discussion}

In this study out of 154 patients with febrile seizures 58 suffered recurrent febrile seizures. The percentage number of recurrent febrile seizures in this study was more than the percentage number in the study conducted by Marudur et al. ${ }^{12}$ in 2012, which was $28.6 \%$. However, it was less than the study conducted in Japan ${ }^{10}$ which was $45 \%$.

Moreover, age is the most consistent risk factor that caused recurrent febrile seizures. The age in this discussion is the age of the patient when the first febrile seizure occurred under 12 months. This is due to febrile seizures have relationships with the maturity level of the brain. In this study, patients with first febrile seizure occurred under 12 months had the highest percentage. This was consistent with studies conducted in Yogyakarta and Iran who claimed that the age at first febrile seizure under 12 months has relationships with the occurrence of febrile seizures. ${ }^{11,12}$

Based on the results, the number of male patients was almost doubled compared to female patients. This was consistent with the studies conducted by Fallah et al. ${ }^{11}$ (2010), Marudur et al. $^{12}$ (2012), and Veisani et al. ${ }^{13}$ (2013) which stated that male suffered more often from febrile seizures compared to female. According to Shinnar ${ }^{1}$ in Swaiman book's Pediatric Neurology, gender is not a risk factor for recurrent febrile seizures. This was consistent with the study conducted by Marudur et al. ${ }^{12}$ which state that gender does not have a relationship to an increased risk of febrile seizures. However, this was contrary to Mikati's statement in Nelson Textbook of Pediatrics that male gender, is a risk factor for the occurrence of recurrent febrile seizures. ${ }^{4}$

In this study, patients with the duration of febrile seizures less than 24 hours had the highest percentage. This was supported by studies conducted by Fallah et al. ${ }^{11}$ (2010) and Marudur et al. ${ }^{12}$ (2012) which stated that the rapid duration of the fever before onset of seizure is a risk factor for the occurrence of recurrent febrile seizures.

Based on the results, it was discovered that febrile seizures with complex febrile seizure types had the highest percentage. This was contrary to the studies conducted by Marudur et al. ${ }^{12}$ (2012) and Veisani et al. ${ }^{13}$ (2013), which stated febrile seizures with simple febrile seizure types had a greater number than the number of febrile seizures with complex febrile seizure types.

In this study, the number of patients who did not have a family history of febrile seizures was higher in percentage than patients who had a positive family history of febrile seizures. This was consistent with studies conducted in Iran and Turkey, however this result was contrary to studies conducted by Fallah et al. ${ }^{11}$ (2010), Marudur, et al. ${ }^{12}$ (2010), and Tosun et al. $^{14}$ (2010). A family history with febrile seizures was a risk factor for the occurrence of febrile seizures. ${ }^{1,4,9}$ This was caused by febrile seizures derived through autosomal dominant gene and a variety of single genes associated with febrile seizures. ${ }^{4}$

The results showed that most children did not have a family history of epilepsy. These results were similar to studies conducted in Yogyakarta. ${ }^{12}$ While the study conducted in Iran and Turkey had a greater percentage. ${ }^{11,14}$

There were limitations to this study regarding the data such as numerous patient medical records were not available, therefore a lot of patient data could not be used in this study. In addition, some medical records did not include the age when the first febrile seizure occurred, duration of the fever to seizure, febrile seizure type and family history of febrile seizures, whereas they were very important to determine the risk of recurrent febrile seizures. Furthermore, the medical records contained no data on body temperature during a febrile seizure; it should have been asked to the parents about their children's body temperature when the seizure occurred. Due to the importance of these medical records as a source of a study, the medical record system at RSHS should pay attention to the completeness in recording patient's data. Moreover, a study with primary data needs to be conducted so that the data obtained may be more accurate, besides an analytic study related risk factors for recurrent febrile seizures is also needed.

The conclusion of this study, the risk groups have a greater percentage when compared to the non-risk group. However, the group with a positive family history of febrile seizures and those with a positive family history of epilepsy 
have a low percentage compared to the nonrisk group, the group with a negative family history of febrile seizures or epilepsy.

\section{References}

1. Shinnar S. Febrile seizures. In: Swaiman KF, Ashwal S, Ferriero DM, Schor NF, editors. Swaiman's pediatric neurology, principles and practice. $5^{\text {th }}$ ed. Edinburgh: Elsevier Health Sciences; 2012. p. 790-7.

2. Kundu GK, Rabin F, Nandi E, Sheikh N, Akhter S. Etiology and risk factors of febrile seizure an update. Bangladesh J Child Health. 2010;34(3):103-12.

3. Kanemura H, Sano F, Mizorogi S, Tando T, Sugita K, Aihara M. Parental thoughts and actions regarding their child's first febrile seizure. Pediatr Int. 2013;55(3):315-9.

4. Mikati MA. Seizures in childhood. In: Kliegman R, Stanton BF, Schor NF, Geme III JWS, Behrman RE, editors. Nelson textbook of pediatrics. $19^{\text {th }}$ ed. Philadelphia: Elsevier/Saunders; 2011.p. 2017-18.

5. Graves RC, Oehler K, Tingle LE. Febrile seizures: risks, evaluation, and prognosis. Am Fam Physician. 2012;85(2):149-53.

6. Wolf P, Shinar S. Febrile seizure. In: Maria BL, editor. Current management in child neurology. $4^{\text {th }}$ ed. Shelton: BC Decker;
2009. p. 99-104.

7. Syndi Seinfeld D, Pellock J. Recent research on febrile seizures: a review. J Neurol Neurophysiol. 2013;4(4):165-171.

8. Chung S. Febrile seizures. Korean J Pediatr. 2014;57(9):384-95.

9. UKK Neurologi IDAI. Kosensus penatalaksanaan kejang demam. In: Hardiono DP, Dwi PW, Sofyan I, editors. $2^{\text {th }}$ ed. Jakarta: Badan Penerbit IDAI; 2006. p. 6.

10. Sugai K. Current management of febrile seizures in Japan: an overview. Brain Dev. 2010;32(1):64-70.

11. Fallah R, Karbasi SA. Recurrence of febrile seizure in Yazd, Iran. Turk J Pediatr. 2010;52(6):618-22.

12. Marudur PT, Herini ES, Satria CD. Predictive factors for recurrent febrile seizures in children. Paediatr Indones. 2012;52(6):317-23.

13. Veisani Y, Delpisheh A, Sayemiri K. Predictors of recurrent febrile seizures in Iranian Children. Zahedan J Res Med Sci. 2013;15(9):1-5.

14. Tosun A, Koturoglu G, Serdaroglu G, Polat M, Kurugol Z, Gokben S, et al. Ratios of nine risk factors in children with recurrent febrile seizures. Pediatr Neurol. 2010;43(3):177-82. 